\title{
The effect of particle acidity on secondary organic aerosol formation from $\alpha$-pinene photooxidation under atmospherically relevant conditions
}

Yuemei Han et al.

Correspondence to: Yuemei Han (yuemeihan@ hotmail.com) and Craig A. Stroud (craig.stroud@ canada.ca)

The copyright of individual parts of the supplement might differ from the CC-BY 3.0 licence. 


\section{S1 High-NO $\mathrm{x}_{\mathrm{x}}$ regime assessment}

The Master Chemical Mechanism (MCM v3.3.1, http://mcm.leeds.ac.uk/MCMv3.3.1/home.htt) was incorporated into a box model to assess the $\mathrm{NO}_{\mathrm{x}}$ regime for the gas-phase reactions of $\alpha$-pinene photooxidation under high- $\mathrm{NO}_{\mathrm{x}}$ conditions The box model was constrained with the initial experimental conditions including temperature, pressure, and the concentrations of $\alpha$-pinene, $\mathrm{NO}$, water vapor, and $\mathrm{H}_{2} \mathrm{O}_{2}$ for the individual chamber experiments in this study. The photooxidation reaction of $\alpha$-pinene was simulated for 6 hours with the box model. The output of the box model was the time series of the concentrations of $\alpha$-pinene, $\mathrm{NO}, \mathrm{O}_{3}, \mathrm{HO}_{2}$, and organic peroxy radicals $\left(\mathrm{RO}_{2}\right)\left(\right.$ molecule $\left.\mathrm{cm}^{-3}\right)$ from each time step with a 1-min resolution. The fraction of $\mathrm{RO}_{2}$ radicals reacted with $\mathrm{NO}$ compared to the total reacted $\mathrm{RO}_{2}$ radicals (with $\mathrm{NO}, \mathrm{HO}_{2}$, and $\mathrm{RO}_{2}$ ) was calculated by

$$
\frac{k_{\mathrm{NO}}[\mathrm{NO}]}{k_{\mathrm{NO}}[\mathrm{NO}]+k_{\mathrm{HO}_{2}}\left[\mathrm{HO}_{2}\right]+k_{\mathrm{RO}_{2}}\left[\mathrm{RO}_{2}\right]}
$$

where $k_{\mathrm{NO}}, k_{\mathrm{HO} 2}$, and $k_{\mathrm{RO} 2}$ are the reaction rates of $\mathrm{RO}_{2}+\mathrm{NO}, \mathrm{RO}_{2}+\mathrm{HO}_{2}$ and $\mathrm{RO}_{2}+\mathrm{RO}_{2}$, respectively and [NO], [ $\left.\mathrm{HO}_{2}\right]$, and $\left[\mathrm{RO}_{2}\right]$ are the concentration of $\mathrm{NO}, \mathrm{HO}_{2}$, and $\mathrm{RO}_{2}$, respectively. The results from the box model are presented in Figure S1. At the start of the simulations, more than $99 \%$ of the $\mathrm{RO}_{2}$ radicals were reacting with $\mathrm{NO}$; while by the end of the experiments (after 6 hours), at least $62 \%$ of the $\mathrm{RO}_{2}$ radicals continued to react with $\mathrm{NO}$ (Figure S1a). The time series for $\alpha$ pinene, $\mathrm{NO}$, and $\mathrm{O}_{3}$ from the measurements were reasonably well captured by the box model (Figure $\mathrm{S} 1 \mathrm{~b}$, c, and d). 

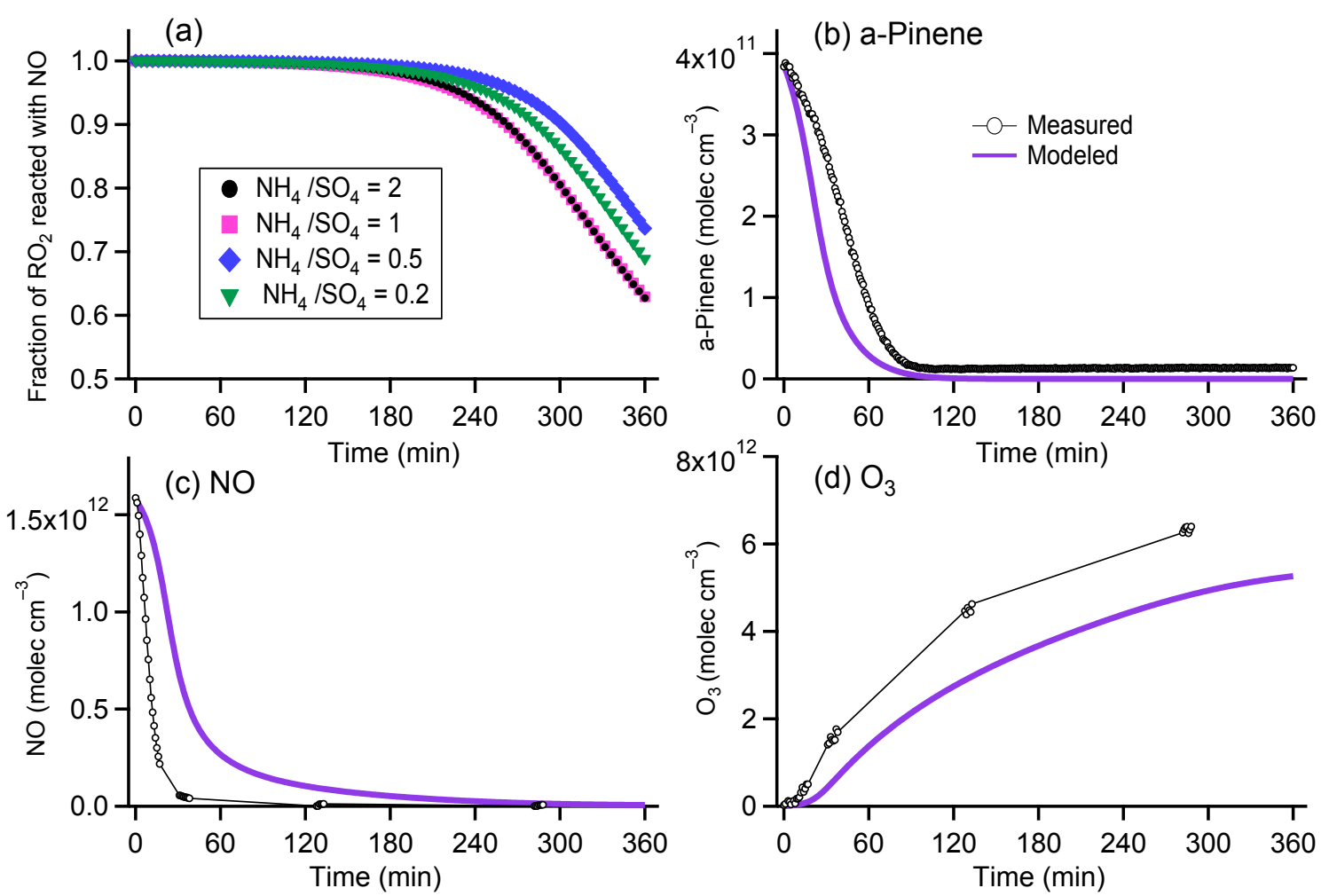

Figure S1. (a) Fraction of $\mathrm{RO}_{2}$ reacted with NO compared to the total reacted $\mathrm{RO}_{2}$ radicals for high-NO ammonium sulfate and acidic seed particles. The measured and the modeled time series of the concentrations of (b) $\alpha$-pinene, (c) $\mathrm{NO}$, and (d) $\mathrm{O}_{3}$ for the high- $\mathrm{NO}_{\mathrm{x}}$ experiment with ammonium sulfate particles $\left(\mathrm{NH}_{4} / \mathrm{SO}_{4}=2\right)$. The variations in time for each species in all experiments with acidic particles under high-NO $\mathrm{N}_{\mathrm{x}}$ conditions are similar to (b), (c), and (d). 


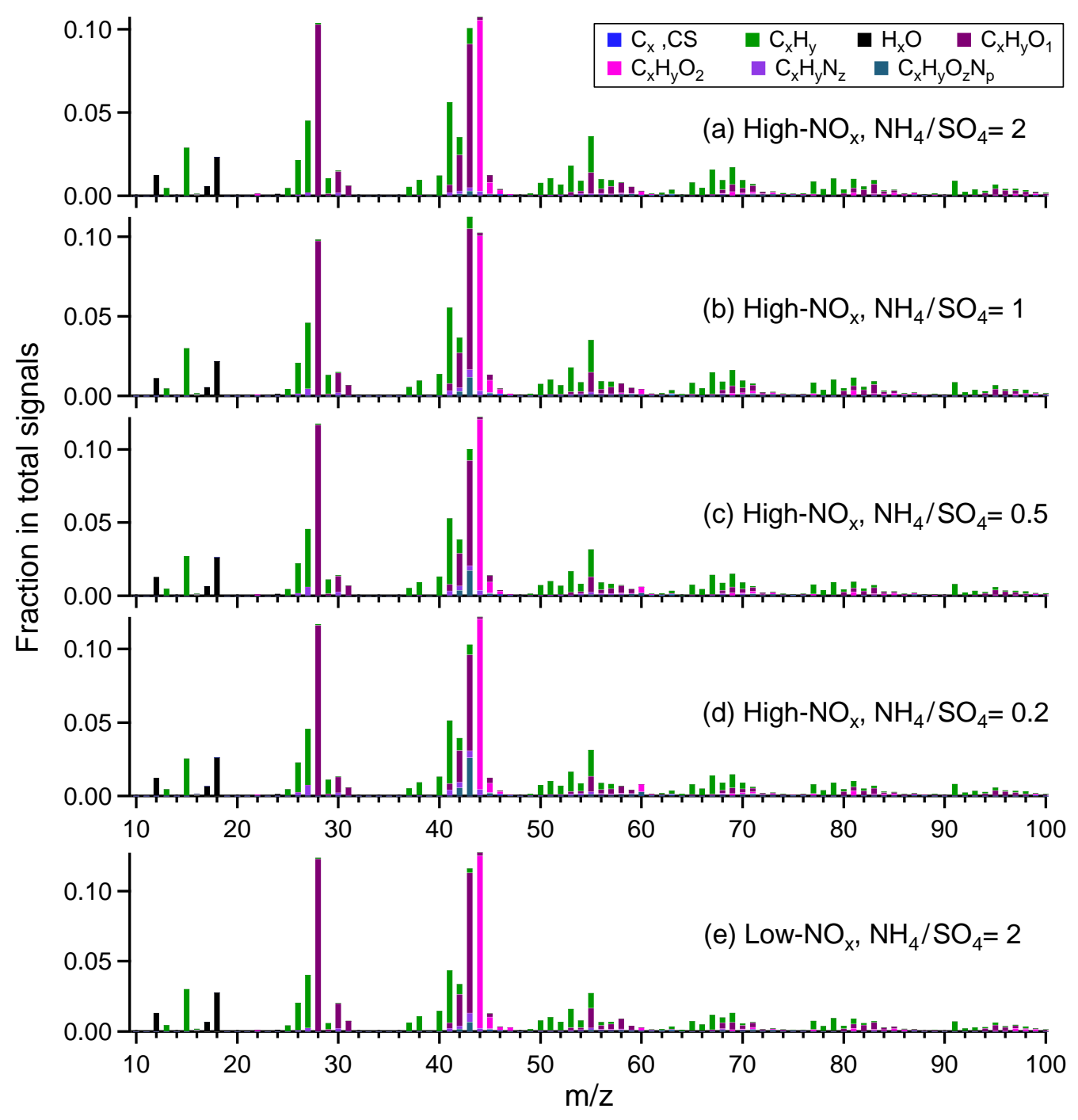

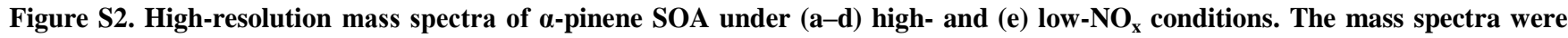
averaged on the irradiation times of 1-5 h and 2-12 h under high- and low-NO conditions, respectively. The mass spectra of $\alpha$ pinene SOA under low-NO $\mathrm{N}_{\mathrm{x}}$ conditions for acidic particles, which are not presented here, resemble that of ammonium sulfate particles in (e). 